\title{
Interventional Influence of the Intestinal Microbiome Through Dietary Intervention and Bowel Cleansing Might Improve Motor Symptoms in Parkinson's Disease
}

\author{
Tobias Hegelmaier ${ }^{1,+}{ }^{\dagger}$, Marco Lebbing ${ }^{2,+}$, Alexander Duscha ${ }^{1}$, Laura Tomaske ${ }^{1}$, Lars Tönges ${ }^{1}{ }^{(D)}$, \\ Jacob Bak Holm ${ }^{3}$, Henrik Bjørn Nielsen ${ }^{3}$, Sören G. Gatermann ${ }^{4}$, Horst Przuntek ${ }^{2}$ and \\ Aiden Haghikia ${ }^{1, *}$ \\ 1 Department of Neurology, Ruhr-University Bochum, St. Josef-Hospital Bochum, Bochum, 44791, Germany; \\ tobias.hegelmaier@googlemail.com (T.H.); Alexander.Duscha@ruhr-uni-bochum.de (A.D.); \\ Laura.Ackermann@ruhr-uni-bochum.de (L.T.); lars.toenges@rub.de (L.T.) \\ 2 Clinic of Neurology II, EVK Hattingen, Hattingen 45525, Germany; marco.lebbing@googlemail.com (M.L.); \\ przuntekh@t-online.de (H.P.) \\ 3 Clinical Microbiomics A/S, Copenhagen 2200, Denmark; jacob@clinical-microbiomics.com (J.B.H.); \\ hbjorn@clinical-microbiomics.com (H.B.N.) \\ 4 Department of Medical Microbiology, Ruhr-University Bochum, Bochum, 44801, Germany; \\ soeren.gatermann@rub.de \\ * Correspondence: aiden.haghikia@rub.de; Tel.: +49-234-509-2411; Fax: +49-234-509-2414 \\ + These authors contributed equally to this work.
}

Received: 23 November 2019; Accepted: 1 February 2020; Published: 6 February 2020

\begin{abstract}
The impact of the gut microbiome is being increasingly appreciated in health and in various chronic diseases, among them neurodegenerative disorders such as Parkinson's disease (PD). In the pathogenesis of $\mathrm{PD}$, the role of the gut has been previously established. In conjunction with a better understanding of the intestinal microbiome, a link to the misfolding and spread of alpha-synuclein via inflammatory processes within the gut is discussed. In a case-control study, we assessed the gut microbiome of 54 PD patients and 32 healthy controls (HC). Additionally, we tested in this proof-of-concept study whether dietary intervention alone or additional physical colon cleaning may lead to changes of the gut microbiome in PD. 16 PD patients underwent a well-controlled balanced, ovo-lacto vegetarian diet intervention including short fatty acids for 14 days. 10 of those patients received additional treatment with daily fecal enema over 8 days. Stool samples were collected before and after 14 days of intervention. In comparison to $\mathrm{HC}$, we could confirm previously reported PD associated microbiome changes. The UDPRS III significantly improved and the levodopa-equivalent daily dose decreased after vegetarian diet and fecal enema in a one-year follow-up. Additionally, we observed a significant association between the gut microbiome diversity and the UPDRS III and the abundance of Ruminococcaceae. Additionally, the abundance of Clostridiaceae was significantly reduced after enema. Dietary intervention and bowel cleansing may provide an additional non-pharmacologic therapeutic option for PD patients.
\end{abstract}

Keywords: vegetarian diet; enema; Parkinson's disease; microbiome; butyric acid

\section{Introduction}

Parkinson's disease (PD) is one of the most common neurodegenerative disorders only second to Alzheimer's disease and the most common movement disorder worldwide [1]. The cause of non-monogenic forms of PD is still not fully understood. PD is a multifactorial disorder with a 
strong environmental component. Mitochondrial dysfunction, oxidative stress, intracellular protein accumulation and abnormal protein degradation are the pathogenic hallmarks of PD [2]. Although the diagnosis of PD is mainly based on the clinical manifestation of extrapyramidal motor symptoms, non-motor symptoms often precede the diagnosis by decades [1]. These include deficits of the autonomic nervous system, olfactory function and symptoms linked to lower brainstem and cerebral cortex. Gastrointestinal dysfunction, for example, obstipation affects more than $80 \%$ of patients with PD [1,3].

There is growing evidence that the microbiome is altered in numerous neurodegenerative diseases, in particular Parkinson's disease. In addition to an overall dysbiosis, the most consistent changes were, besides an increase in the relative abundances of Verrucomicrobiaceae and Akkermansia, a decrease of Prevotellacae [4-9]. In this context, Keshavarzian et al. found a pro-inflammatory microbiome with an increase of Proteobacteria of the genus Ralstonia while the potential anti-inflammatory butyrate-producing bacteria Blautia, Coprococcus and Roseburia were reduced in PD [7,8]. For a long time now, it has been hypothesized that the gut may play a crucial role in the etiology of PD. The intestinal microbiome with a similar amount of bacterial cells as human cells, could be the decisive factor linking the environment and neuronal damage in the central nervous system (CNS) of PD patients [10-12]. According to the first theory, alpha-synuclein accumulates in the enteric nervous system and retrogradely extends to the brain stem via the vagus nerve and its nucleus dorsalis $[13,14]$. Further support for the gut-theory can be deduced from the epidemiological observation that vagotomized individuals have a reduced risk of PD [15]. However, this hypothesis was challenged by a Swedish register-based matched-cohort study that could not detect a reduced risk for the development of PD by vagotomy in general. Nevertheless, a sub analysis revealed a reduced risk through a truncal vagotomy [16]. In recent years, alternative ways of communication between the intestine and the brain have been discussed. In addition to the neural path, there is evidence that the endocrine and blood system plays a decisive role [17]. According to the proinflammatory gut microbiome growing evidence support the hypothesis that inflammatory processes play an important role in PD and might be a further pathway of the gut-brain-axis [18,19]. Supporting this notion, different retrospective studies exposed a higher incidence of PD in patients with chronic inflammatory bowel diseases [20]. This hypothesis coincides with the detection of proinflammatory markers in stool samples. Calprotectin is a marker for increased activity of the immune system, which is used to monitor inflammatory bowel disease (IBD). It has been shown that calprotectin is also elevated in the stool samples of patients with PD [21,22]. Further inflammatory markers (Il-1b, Il-1a, fecal C-reactive protein and CXCL8 (Il-8)) have been detected by Houser et al. in stool and by Deros et al. in colon biopsies of PD patients [23,24]. In addition, increased permeability markers in the feces of PD patients were also detected with zonulin and alpha-trypsin [21]. A higher permeability and disrupted occludin, controlling intestinal barrier permeability, have been found in PD patients $[25,26]$, which may lead to increased transition of pro-inflammatory cytokines that have been observed within the colon of patients with PD [24]. These results strongly support the hypothesis that micro inflammation with increased intestinal permeability and a potential leaky-gut syndrome with the absorption of endotoxins plays a crucial role in PD. Additional to the proinflammatory intestinal environment, there are indications that the increased inflammatory activity is associated with an elevated concentration of alpha-synuclein. According to this Keshavarzian et al. hypothesized that the dysbiosis could potentially trigger inflammation-induced misfolding of a-Syn in PD $[8,27]$.

In addition to increased local inflammatory activity in the intestine, there is also evidence of increased systemic inflammatory activity in Parkinson's disease. Thus, the working group around Williams-Grey and Bordacki detected increased levels of proinflammatory cytokines such as TNF-a, INF-gamma IL1-b, IL-2, IL-4, IL-6 and IL-10 within the blood of PD patients [28,29]. In this context, it has already been suspected that proinflammatory cytokines lead to a disruption of the blood-brain barrier and consequently are indirectly involved in the activation of glial cells [18,19].

Besides inflammatory changes within all levels of the gut-brain axis further evidence pointing to a major impact of the microbiome on the clinical course. Therefore, in a mouse model of PD 
transplantation of the microbiome of patients with PD into receptive mice led to motor symptoms as opposed to the transplant sample of healthy individuals [30]. Furthermore, recently it has also been shown that gut-associated bacteria differ in their ability to decarboxylate levodopa to dopamine via tyrosine decarboxylases in the proximal small intestine and thereby influence the levodopa dosages needed for symptom control [31]. In this regard, a conserved tyrosine decarboxylase (TyrDC) has been detected within Enterococcus faecalis [32]. In addition, a negative correlation between the frequency of Firmicutes and the use of entacapone has been reported [7]. These data suggest that in future the microbiome might be a crucial component in the management of side effects as well as in the therapy of PD.

The influence of the microbiome on the clinical course raises the question of potential therapies that can positively influence the microbiome. It has been researched that a vegetarian diet causes an anti-inflammatory effect in healthy subjects. With regard to the proinflammatory intestinal environment in $\mathrm{PD}$, we investigated the influence of a vegetarian diet including a high proportion of anti-inflammatory acting short-fatty acids (SCFA) on the microbiome and the clinical course in patients with PD. Another therapy for IBD are rectal enemas. For this reason, in this proof-concept study, we have also looked in a small cohort at the influence of enemas on the microbiome and the clinical course.

\section{Materials and Methods}

\subsection{Participants}

The study was performed from November 2013 to January 2015 (gut microbiome analysis was approved by the Ethics Committee of the Ruhr-University Bochum; registration number 4493-12). Patients were recruited from the Department of Neurology of the University Hospital St. Josef-Hospital Bochum and from the Clinic of Neurology in Hattingen (Klinik für Neurologie II und Komplementärmedizin, Evangelisches Krankenhaus Hattingen, Germany). Written informed consent was obtained from all patients and healthy participants.

Inclusion criteria for PD patients comprised the diagnosis of non-monogenic forms of PD. Further, all patients were independently mobile and completely orientated for time, location, person and situation. Exclusion criteria comprised poor general condition, serious concomitant disease or organ dysfunction, insufficient German language skills, severe psychiatric diseases, serious pre-existing conditions of the gastrointestinal tract, malignancies, pregnancy and missing informed consent.

Healthy subjects served as controls (HC) and were at an age between 18 to 85 years. HC were excluded when any of the following diseases were present: chronic gastrointestinal disease; chronic systemic autoimmune disease with GI involvement; neurological disease; psychiatric diseases; malignancies. Furthermore, the detection of systemic infections or pathogenic bacterial strains in feces or systemically, and holiday history in risk areas (tropical countries, countries with risk of travel diarrhea) within the last 6 months or medication history affecting the microbiome, that is, antibiotics within the last 6 months, were considered as exclusion criteria.

For microbiome analysis, we enrolled 54 patients with idiopathic PD and $32 \mathrm{HC}$ (demographic details enlisted in Table 1). Additionally, from 16 of these patients a stool sample was taken before and after 14 days of dietary intervention with or without bowel cleansing (demographic details enlisted in Table 2). The detailed schedule is shown graphically in Figure 1. 
Table 1. Demographic data and characteristics including standard deviation or percentage data of patients without therapeutic intervention and healthy subjects (the given data are complete for all participants).

\begin{tabular}{|c|c|c|c|}
\hline Characteristics & PD $(n=54)$ & HS $(n=34)$ & $p$ \\
\hline Female sex, n (\%) & $27(50 \%)$ & $20(58.8 \%)$ & $0.425^{\mathrm{a}}$ \\
\hline Age, years, mean $\pm S D$ & $61( \pm 9.2)$ & $52.8( \pm 12.6)$ & $0.00^{\mathrm{b}}$ \\
\hline Disease duration, years, mean \pm SD & $9.1( \pm 5.8)$ & & \\
\hline BMI & $26.15( \pm 4.5)$ & $26.1( \pm 5.5)$ & $0.952^{b}$ \\
\hline Subgroupsakinetic-rigid & $23(42.6 \%)$ & & \\
\hline equivalent & $25(46.3 \%)$ & & \\
\hline tremordominant & $6(11.1 \%)$ & & \\
\hline Medication & & & \\
\hline L-Dopa (mg) daily dose & $388( \pm 276)$ & & \\
\hline Benserazid & $37(68.5 \%)$ & & \\
\hline Carbidopa & $20(37 \%)$ & & \\
\hline Entacapon & $13(24.1 \%)$ & & \\
\hline MAO-B Hemmer & $39(72 \%)$ & & \\
\hline Dopamine agonists & $40(74.1 \%)$ & & \\
\hline Amantadine & $25(46.3 \%)$ & & \\
\hline Anticholinergics & $1(1.9 \%)$ & & \\
\hline Proton pump inhibitor & $5(9.3 \%)$ & $2(5.9 \%)$ & $0.622^{c}$ \\
\hline Vegetarian & $5(9.3 \%)$ & $3(8.8 \%)$ & $0.333^{c}$ \\
\hline Mostly (rarely meat) & $16(29.6 \%)$ & $5(14.7 \%)$ & $0.836^{\mathrm{c}}$ \\
\hline Vegan & $1(1.9 \%)$ & $0(0 \%)$ & $0.433^{c}$ \\
\hline How often meat per week & & & $0.069^{\mathrm{c}}$ \\
\hline Non & $9(16.7 \%)$ & $4(11.8 \%)$ & \\
\hline $1-2$ & $14(25.9 \%)$ & $5(14.7 \%)$ & \\
\hline $3-5$ & $20(14.8 \%)$ & $9(26.5 \%)$ & \\
\hline $6-7$ & $8(37 \%)$ & $13(38.2 \%)$ & \\
\hline Bristol Stool scale & & & $0.418^{\mathrm{c}}$ \\
\hline 1 & $21(38.9 \%)$ & $9(26.5 \%)$ & \\
\hline 2 & $13(24.1 \%)$ & $12(35.3 \%)$ & \\
\hline 3 & $12(22.2 \%)$ & $12(35.3 \%)$ & \\
\hline 4 & $8(14.8 \%)$ & $5(14.7 \%)$ & \\
\hline 5 & 0 & 0 & \\
\hline 6 & 0 & 0 & \\
\hline 7 & 0 & 0 & \\
\hline \multicolumn{4}{|c|}{ Unified Parkinson Disease Rating Scale (UPDRS) } \\
\hline UPDRS I & $2( \pm 1.9)$ & & \\
\hline UPDRS II & $7.2( \pm 4.6)$ & & \\
\hline UPDRS III & $14.9( \pm 10.4)$ & & \\
\hline UPDRS IV & $1.8( \pm 2.3)$ & & \\
\hline UPDRS V & $1.8( \pm 0.6)$ & & \\
\hline UPDRS VI & $0.9( \pm 0.1)$ & & \\
\hline
\end{tabular}

Table 2. Demographic data and characteristics of patients with therapeutic intervention (the given data are complete for all participants).

\begin{tabular}{cc}
\hline Characteristics & PD $(\boldsymbol{n = 1 6 )}$ \\
\hline Female sex, $\mathrm{n}(\%)$ & $10(63 \%)$ \\
Age, years, mean \pm SD & $64 \pm 5.4$ \\
Disease duration, years, mean \pm SD & $8.6 \pm 4.1$ \\
BMI & $26.7 \pm 4$ \\
Vegetarian & $1(6.3 \%)$ \\
Mostly (rarely meat) & $4(25 \%)$ \\
Vegan & $1(6.3 \%)$ \\
How often meat per week & \\
Non & $0(0 \%)$ \\
$1-2$ & $5(31.3 \%)$ \\
$3-5$ & $8(50 \%)$ \\
$6-7$ & $3(18.8 \%)$ \\
\hline
\end{tabular}




\section{Timetable [day]}

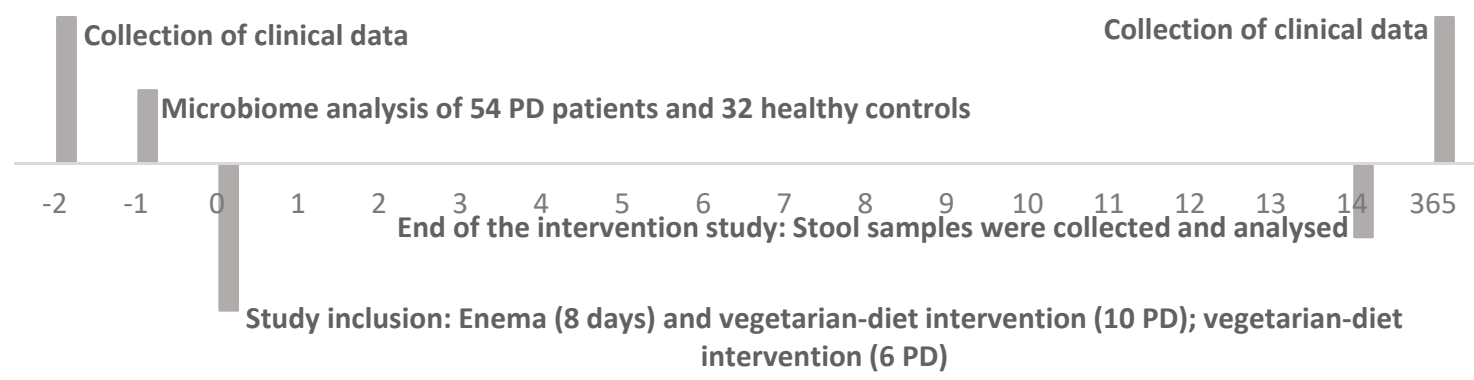

Figure 1. Timetable of study characteristics in days.

\subsection{Bowel Cleansing}

In advance, all patients received safety examinations including electrocardiography, as well as routine blood tests. During the procedure the blood pressure, oxygen saturation and pulse rate was measured.

Since there is no international standard procedure for enema, we decided to use an oil enema for an adequate lubrication and as a stool softener because of the increased obstipation tendency in PD. Bowel cleansing was performed on 8 consecutive days. Before the procedure, the decoction was prepared with warm water with electrolytes (water temperature was adjusted to $38^{\circ} \mathrm{C}$ ). Furthermore, $120 \mathrm{~mL}$ oil was continuously stirred until a uniform consistency was attained. Nursing care, including psychologic care and abdominal massage was provided during the entire procedure.

Between 11.00 to $12.00 \mathrm{am}$, shortly before lunch, the procedure was performed according to the following standard operating procedures: Patients were placed in a supine position on a bed. A small amount of oil was applied to the anal canal for lubrication, then a rectal examination was carried out to rule out loaded rectum or any other obstruction. Afterwards the tip of the irrigator was gently introduced into the anus and the height was unadjusted slowly and steadily to allow the decoction into the patient's rectum. Patients were instructed to breathe deeply to relax the anal canal before insertion. Until the urge of defecation occurs, the patients were asked to lie in supine position. The procedure lasted for approximately $30 \mathrm{~min}$.

Possible contraindications for enemas were multiple abdominal surgery in history, gastrointestinal bleeding, vomiting, abdominal pain, malignancies, as well as hemorrhoids and severe heart disease.

Possible side effects of the enemas are orthostatic dysregulation, electrolyte imbalance, exsiccosis, infections, abdominal pain, diarrhea, nausea and vomiting.

\subsection{Dietary Intervention}

All patients received a balanced, vegetarian regimen in an ovo-lacto vegetarian style including ghee during the observation period of 14 days. The participants received three meals a day. One meal in the morning, noon and evening. $45 \%$ of the dishes contained ghee that contains up to $30 \%$ butyric acid. All ingredients including spices, herbs, oils, seeds, nuts and kernels of all meals during the 14 days are listed in Table 3. 
Table 3. Ingredients during the two-week diet which all patients with Parkinson's disease (PD) have received.

\begin{tabular}{|c|c|}
\hline Nutrition's & \\
\hline Ghee & $\begin{array}{l}\text { Ghee is a pure clarified fat exclusively obtained from milk, cream or butter. Almost a } \\
\text { total removal of water and non-fat solids with a total fat content of } 62 \% \text { is achieved. }\end{array}$ \\
\hline Vegetables & $\begin{array}{l}\text { Onions, garlic, potatoes, carrots, chives, spinach, lentils, tomatoes, auberges, ginger, } \\
\text { zucchini, rucola, cauliflower, fennel, broccoli, celery, leek, chicory, swiss chard, Chinese } \\
\text { cabbage, kohlrabi, Muscat pumpkin, beetroot, chickpeas, mung beans, Lollo rosso, } \\
\text { spring onions, cucumber, iceberg lecture, paprika. }\end{array}$ \\
\hline Fruits & $\begin{array}{l}\text { Lemon, raspberry, strawberry, raisin, apple, radish, mango, figs, coconut, physialis, } \\
\text { pineapple, peach, plums, oranges, grapes, cantaloupe melon, pomegranate, kiwi, } \\
\text { banana, grapefruit, avocado, olives. }\end{array}$ \\
\hline Cereals & Spelt, wheat, rice (basmati), rye, oats, millet, barley, semolina, maize. \\
\hline Milk and egg products & $\begin{array}{l}\text { Whole milk, eggs, quark, cream cheese, yogurt, sour cream, rice pudding, low-fat curd } \\
\text { cheese. }\end{array}$ \\
\hline Other & Noodle (spaghetti, penne), amaranth, bulgur, quinoa, ascorbic acid. \\
\hline Spices and herbs & $\begin{array}{l}\text { Vanilla, sugar, salt, pepper, coriander, cinnamon, chili, cardamom, cane sugar, basil, } \\
\text { mint leaves, oregano, mustard, rosemary, marjoram, parsley, curry leaves, thymus, } \\
\text { saffron, bay leaves, tridosha curry, lovage, star anise, ajwain, chervil, lime leaves. }\end{array}$ \\
\hline Nuts, seeds and kernels & $\begin{array}{l}\text { Sesame, almonds, pumpkin seed, cashew, kernel, fennel seed, nutmeg, sunflower seeds, } \\
\text { hazelnuts. }\end{array}$ \\
\hline Oil and vinegar & Olive oil, pumpkin seed oil, balsamic vinegar, walnut oil, sesame oil. \\
\hline Other & Rose water, honey, maple syrup, soy sauce. \\
\hline
\end{tabular}

\subsection{Bristol-Stool-Scale}

The Bristol-stool-scale is a diagnostical tool, designed by the Bristol Royal Infirmary, to classify the form of the human faces into seven categories. This well-established scale is used in clinical and experimental settings and was additionally assessed in PD and HC [33].

\subsection{Sample Acquisition, Preparation and 16sRNA Sequencing}

All patients' fecal samples were collected at the Clinic of Neurology II, EVK Hattingen Germany and were snap frozen immediately at $-80^{\circ} \mathrm{C}$ after defecation. In 16 patients with PD, a sample was collected before, during and after combined treatment including dietary intervention and bowel cleansing.

For the extraction of DNA, a commercial system (QIAamp Fast Stool Mini Kit, Qiagen, Hilden, Germany) was used. In brief, the samples were thawed at $4{ }^{\circ} \mathrm{C}$ and approximately $500 \mathrm{mg}$ was suspended in Inhibitex buffer $(3 \mathrm{~mL})$. Suspensions were heated $\left(95^{\circ} \mathrm{C}, 5 \mathrm{~min}\right)$, spun $(20,000 \times g)$ and the supernatant was used for DNA preparation according to the protocol of the manufacturer. Purity was checked by determining the OD260/OD280 ratio, damage and degradation by agarose gel electrophoresis and absence of inhibitors was verified by amplification with the primers 27F and 534R, which amplify the V1-V3 regions. The 16SrDNA region was amplified with the same primers and sequenced by Illumina technology by a commercial vendor (GATC Biotech, Konstanz, Germany).

\subsection{Unified Parkinson Disease Rating Scale}

The Unified Parkinson Disease Ratings Scale (UPDRS) is the most widely used scale for the clinical evaluation of PD patients. There is UPDRS I-IV. UPDRS I evaluate mentation, behavior and mood, II includes a self-assessment about daily life experience and IV about complications of therapy. UPDRS III is an internationally well-established rating scale for assessing the motor symptoms of patients with PD. It includes assessment of speech, facial expression, rest tremor (face, hands and feet), action or postural tremor of the hands, rigor (neck, arms and legs), finger dexterity (finger tapping), hand movements (opening and closing the hands), rapidly changing hand movements (pronation and 
supination movements), agility of the legs, getting up from the chair, posture, gait, postural stability and brady- and hypokinesia of the body. A score between 0 and 108 can be given [34].

\subsection{Bioinformatic Analysis}

The 32-bit version of USEARCH [35] and mothur [36] was used in combination with several in-house programs for bioinformatics analysis of the sequence data.

Following tag identification and trimming, all sequences from all samples were pooled. Paired-end reads were merged, truncating reads at a quality score of 4 , requiring a merged read length between 300 and $600 \mathrm{bp}$ in 2 length. Sequences with ambiguous bases, without a perfect match to the primers, a homopolymer length greater than 8 , or more than one expected error, were discarded and primer sequences trimmed. Sequences were strictly dereplicated, discarding clusters smaller than 5.

Sequences were clustered at $97 \%$ sequence similarity, using the most abundant strictly dereplicated reads as centroids and discarding suspected chimeras based on internal comparison. Additional suspected chimeric OTUs are discarded based on comparison with the Ribosomal Database Project classifier training set v9 [37] using UCHIME [38]. Taxonomic assignment of OTUs is done using the method by Wang et al. [39] using the database Ribosomal Database Project. Downstream analysis was based on rarified data and performed in R version 3.3 ( $R$ Development Core Team (2008). $\mathrm{R}$ : A language and environment for statistical computing. R Foundation for Statistical Computing, Vienna, Austria. ISBN 3-900051-07-0, URL http://www.R-project.org.) using the vegan package (Jari Oksanen, F. Guillaume Blanchet, Michael Friendly, Roeland Kindt, Pierre Legendre, Dan McGlinn, Peter R. Minchin, R. B. O'Hara, Gavin L. Simpson, Peter Solymos, M. Henry H. Stevens, Eduard Szoecs and Helene Wagner (2016). vegan: Community Ecology Package. R package version 2.4-1. https://CRAN.R-project.org/package=vegan).

\subsection{Statistical Analysis}

All statistical analyses were conducted in SPSS version 25 (IBM, Armonk, NY, USA). T-test was used for interval scaled data. Chi-square tests were used to analyze nominal variables. When appropriate, Fisher's exact test was used. All results are presented as mean \pm standard deviation (SD). A $p$-value $<$ 0.05 was considered to be statistically significant.

\section{Results}

\subsection{Microbiome of PD Patients}

In line with former studies, we could confirm a difference in bacterial composition between patients with PD and HC. None of the changes reached significance (Figure 2). We could show a tendency towards a reduction of Prevotellaceae, Bacteroidetes and the genus Butyricimonas and Odoribacter in PD (Figure 3). Moreover, we could show a relative increase of Actinobacteria and Firmicutes compared to healthy controls. Furthermore, Negativicutes and the phylum Proteobacteria showed a tendency to increase.

\subsection{Microbiome Composition before and after Combined Treatment}

Our data show that the UPDRS III improved and decreased significantly after therapy $(p=0.0004)$. An analysis of the subgroup also showed a significant decrease in the group with vegetarian diet $(p=0.033)$ and the group with additional bowel cleansing $(p=0.005)$ (Figure 4). Analysis of the subgroups revealed no change of the Shannon index before and after therapy in general (Figure 5). 


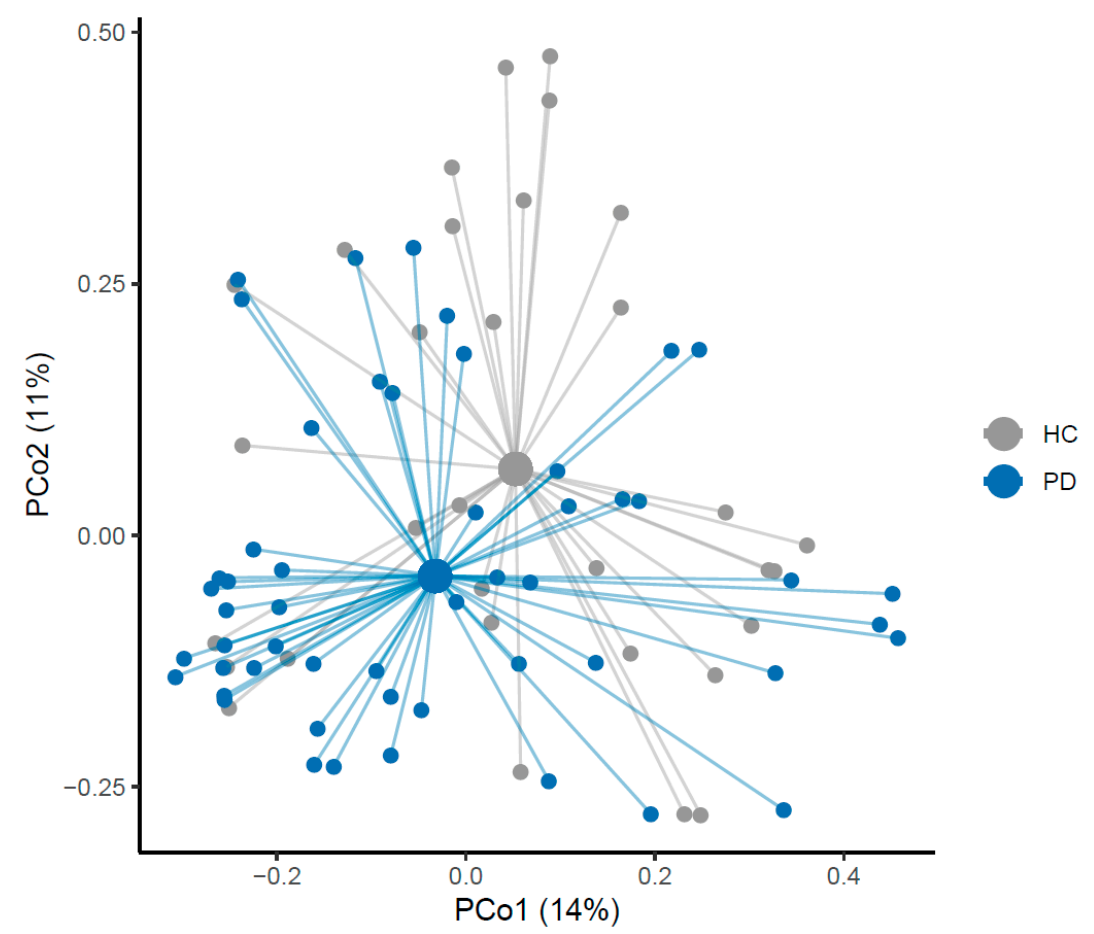

Figure 2. Principal Coordinates Analysis (PCoA) of unweighted UniFrac. HC: Healthy Controls; PD: Parkinson Disease.

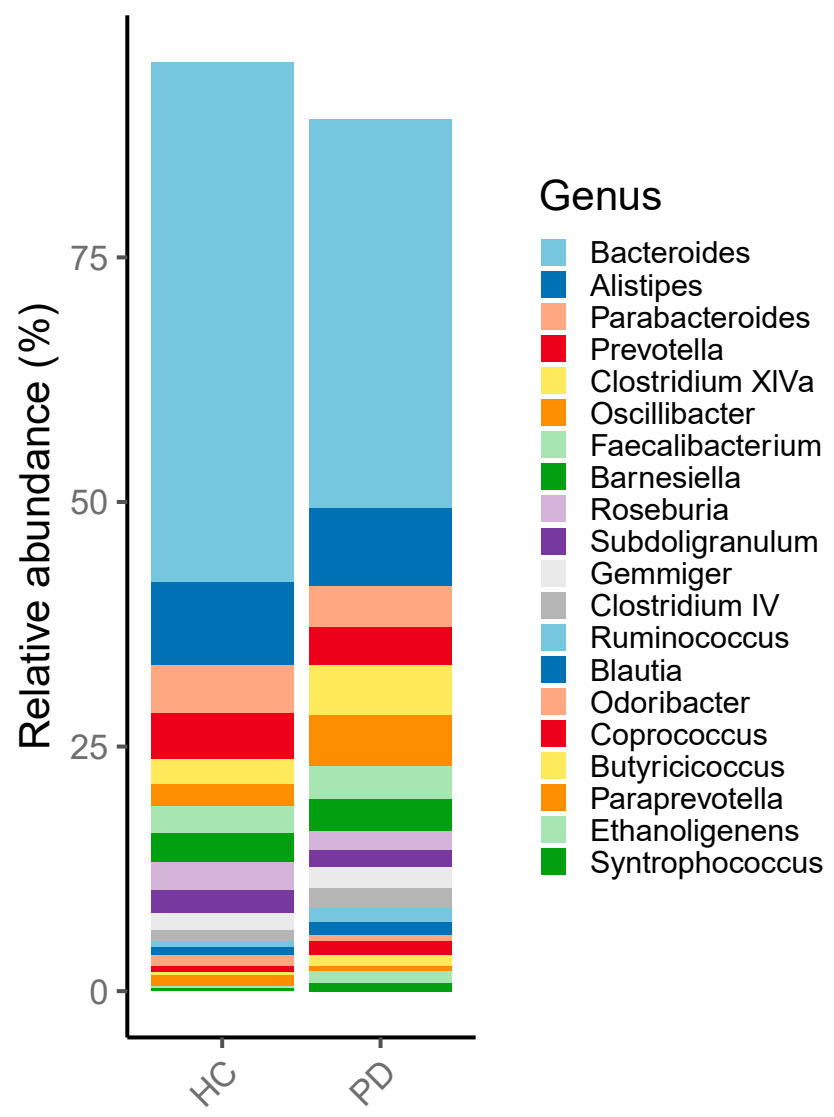

Figure 3. Relative abundance of the genus level in patients with Parkinson disease and healthy controls. HC: Healthy Controls; PD: Parkinson Disease. 

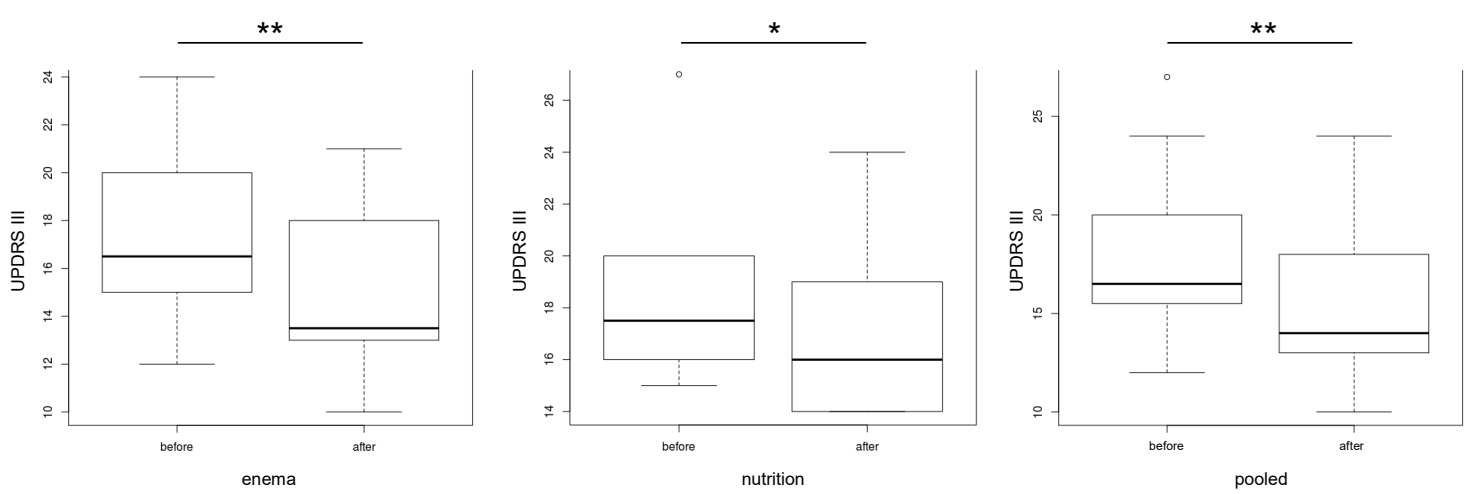

Figure 4. Unified Parkinson Disease Ratings Scale (UPDRS) III before and after one year after the 14 days interval of treatment for each individual group (enema, only nutrition) and for both groups together (pooled) $\left.{ }^{*} p<0.05 ;{ }^{* *} p<0.01\right)$.

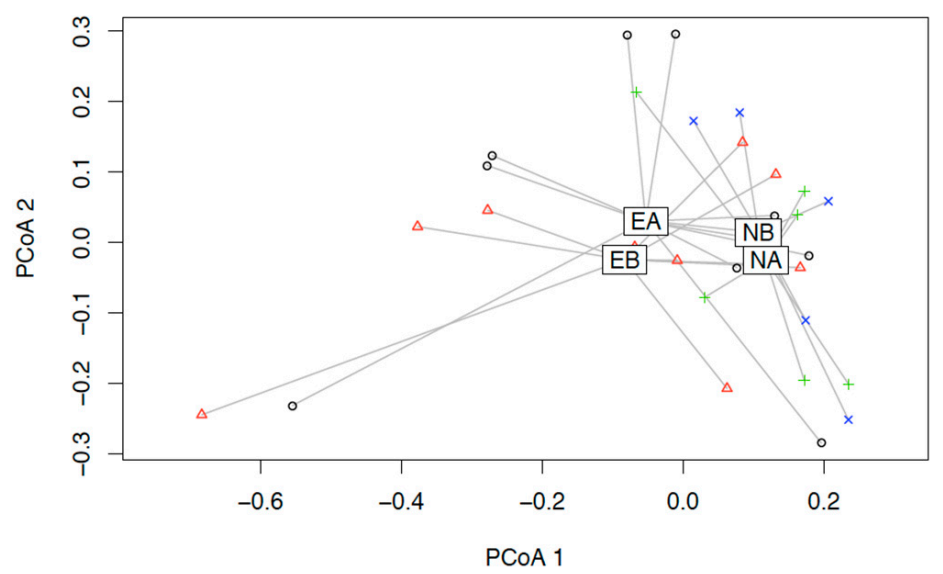

Figure 5. Principal Coordinates Analysis (PCoA) of Bray-Curtis- dissimilarity for the beta-diversity before and after intervention. EB: enema before, EA: enema after intervention; NB: nutrition before, NA: nutrition after intervention.

Interestingly, there was a significant association in the generalized linear model between the Shannon index and the UPDRS III in all groups with therapy $(p=0.006)$ (Figure 6). Furthermore, there was a correlation between the abundance of Ruminococcaceae and the UPDRS III ( $p=0.0003)$ (Figure 7). Only the abundance of Clostridiaceae was significantly reduced after herbal enema $(p=0.043)$ (Figure S1).

\subsection{Dosage of Levodopa before and after One Year}

In a one year follow up of patients who received combined bowel cleansing and dietary intervention, a decrease in levodopa dose of $36 \mathrm{mg} /$ day (mean) was noted. The intervention group with an isolated dietary intervention had an increase of $100 \mathrm{mg}$ of daily levodopa after one year (0.173) (Table 4).

Table 4. Levodopa-equivalent daily dose before and 1 years after therapy including dietary intervention with or without enema (The given data are complete for all participants).

\begin{tabular}{cccc}
\hline & PD without Enema $(\boldsymbol{n}=\mathbf{6})$ & PD with Enema $(\boldsymbol{n}=10)$ & $\boldsymbol{p}$-Value \\
\hline Cum. dopamine doses before therapy $(\mathrm{mg})$ & $263.3(147 \mathrm{mg})$ & $537.6(440.4 \mathrm{mg})$ & $0.388^{\mathrm{a}}$ \\
Cum. dopamine doses one year after therapy $(\mathrm{mg})$ & $346.7(156.9 \mathrm{mg})$ & $481.4(459.8 \mathrm{mg})$ & $0.314^{\mathrm{a}}$ \\
Difference & $83.3 \mathrm{mg}(182.8 \mathrm{mg})$ & $-56.1 \mathrm{mg}(184.5 \mathrm{mg})$ & \\
\hline & ${ }^{\mathrm{a}} t$-test.
\end{tabular}



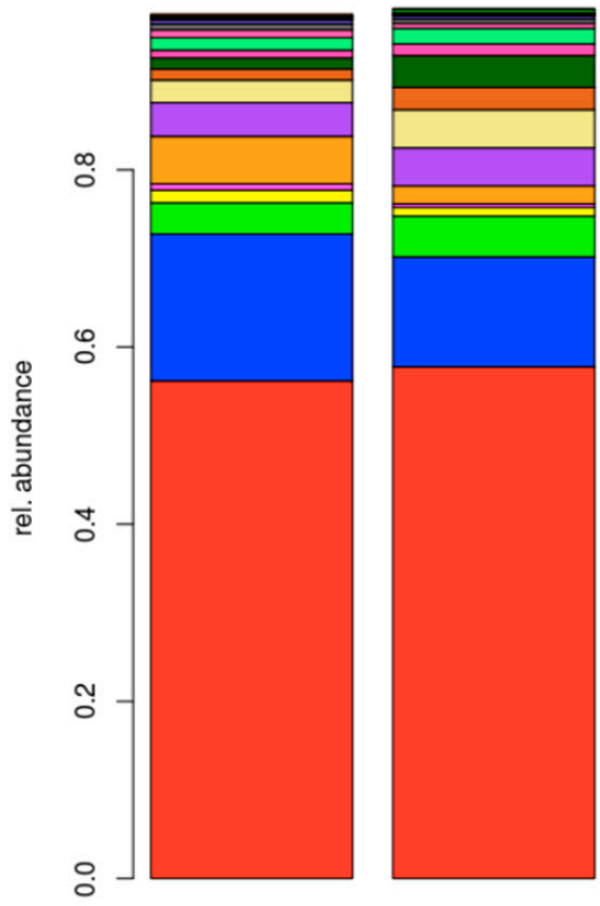

before after

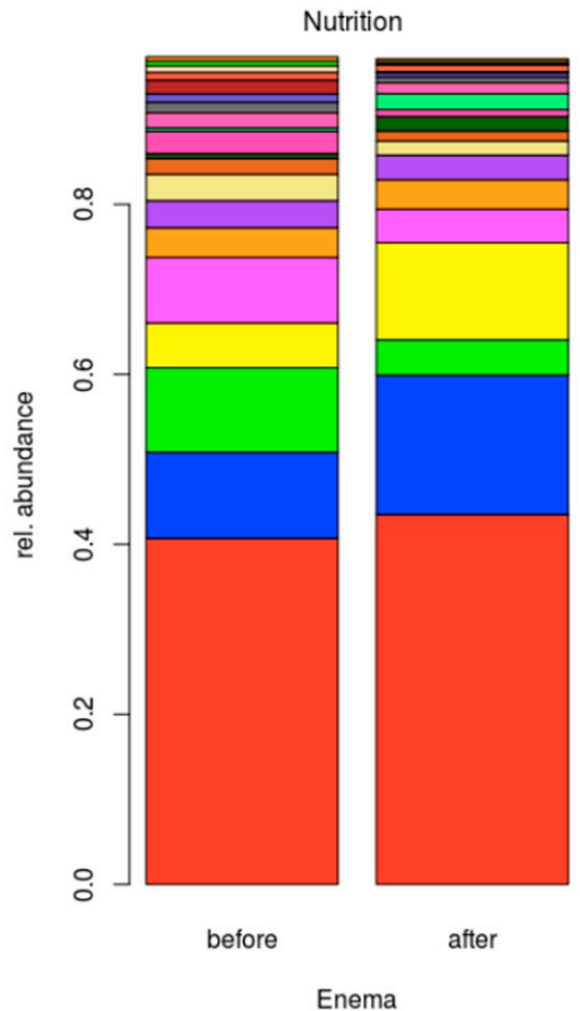

ㅁ Bacteroides

- Alistipes

$\square$ Faecalibacterium

$\square$ Prevotella

$\square$ Dialister

$\square$ Parabacteroides

- Barnesiella

$\square$ Eubacterium

- Clostridium

- Parasutterella

- Roseburia

$\square$ Phascolarctobacterium

$\square$ Oscillibacter

- Odoribacter

- Ruminococcus

- Collinsella

- Paraprevotella

$\square$ Fusicatenibacter

$\square$ Akkermansia

$\square$ Coprococcus

\begin{tabular}{|l|l|}
\hline & Bacteroides \\
$\square$ & Alistipes \\
$\square$ & Faecalibacterium \\
$\square$ Prevotella \\
$\square$ Dialister \\
$\square$ Parabacteroides \\
$\square$ Barnesiella \\
$\square$ Eubacterium \\
$\square$ Clostridium \\
$\square$ Parasutterella \\
$\square$ Roseburia \\
$\square$ Phascolarctobacterium \\
$\square$ Oscillibacter \\
$\square$ Odoribacter \\
$\square$ Ruminococcus \\
$\square$ Collinsella \\
$\square$ Paraprevotella \\
$\square$ Fusicatenibacter \\
$\square$ Akkermansia \\
$\square$ Coprococcus \\
\hline
\end{tabular}

Figure 6. Relative abundance of the genus level in patients with Parkinson disease before and after intervention. 


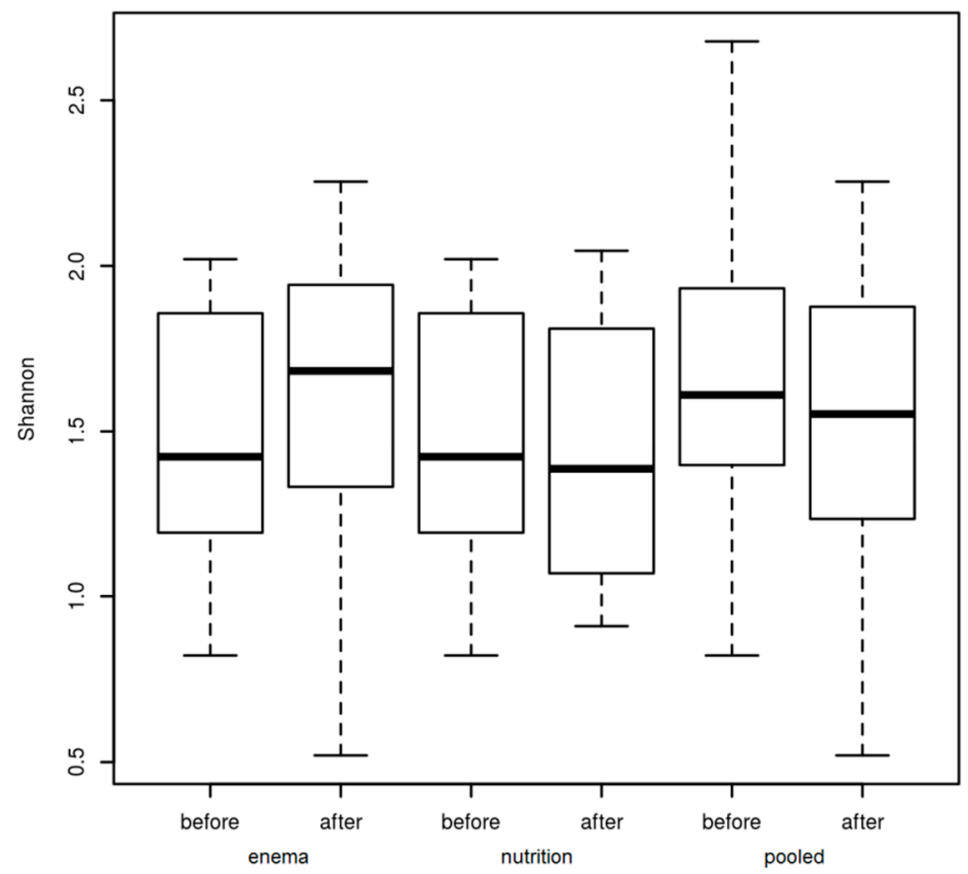

Figure 7. Shannon index before and after the 14 days of therapy for each individual group (enema, only nutrition) and for both groups together (pooled). Box-Whisker-Plots (minimum, 25\%-quartile, median, $75 \%$-quartile, maximum).

\section{Discussion}

In our study, we could corroborate the former results on the dysbalance of the microbiome related to PD, that is, a relative increase of Actinobacteria and Firmicutes compared to healthy controls. Nevertheless, none of those changes reached significance (Figure 2). Additionally, a tendency towards a reduction of Prevotellaceae, Bacteroidetes and the genus Butyricimonas and Odoribacter in PD was present (Figure 3). Furthermore, Negativicutes and the phylum Proteobacteria showed a tendency to increase.

In both subgroups - combined dietary intervention plus bowel cleansing and the isolated dietary intervention group - we observed a significant clinical improvement as quantified by UPDRS III. Furthermore, the study revealed a significant association in the generalized linear model within the pooled group between the Shannon-Index and the UPDRS III $(p=0.006)$, an indicator of bacterial diversity in the gut of PD patients. Interestingly, there was a positive correlation between the UDPRS III and the frequency of Ruminococcaceae. Additionally, the abundance of Clostridiaceae was significantly reduced after enema.

Recently there have been various studies with different approaches examine the gut microbiome in patients with PD. It is now agreed that a shift of the microbiome, that is, towards dysbiosis, is likely linked to disease pathogenesis and not to single aberrant bacterial strains. The complex changes of the microbiome composition might affect metabolic, immunological and homeostatic functions of the host organism $[40,41]$. In this context, Keshavarzian et al. showed that in PD a pro-inflammatory dysbiosis is prevalent and as a result, alpha-synuclein is increased in the gut of PD patients. Therefore, they found reduced levels of "anti-inflammatory" butyrate-producing bacteria from the genus Blautia, Coprococcus and Roseburia [42,43]. Furthermore, an increase of "pro-inflammatory" Proteobacteria of the genus Ralstonia was documented [8]. In our cohort we could also confirm a tendential increase of Proteobacteria and Firmicutes [4-6] in the gut of PD patients as a sign of dysbiosis, a potential 'pro-inflammatory' state and in case of Firmicutes a potential negative influence on the intestinal wall integrity [44,45]. In addition, a negative correlation between the frequency of Firmicutes and the duration of PD has been previously detected, meaning a reduced frequency in elder patients [8]. In line with several studies we could confirm a tendency towards the reduction of the Prevotellaceae [7] 
and Bacteroidetes [5] in PD. Furthermore, in this study we found a significant correlation between the frequency of Ruminococcaceae and the UPDRS-III (Figure 8). This confirms the relevance of the microbiome for the clinical course. Along with two former studies, we found a reduced but not significant frequency of the genus Prevotella [5]. Moreover, Prevotella enrichment has been linked to a rich-fiber diet, which is the primary source for SFCA including butyrate [46,47]. A lack of Butyrate has been substantiated in PD and is associated to disrupt barrier function and enhanced promote inflammation $[7,46,48]$. In this context Unger et al. detected a decreased level of SCFA within stool samples of PD patients [7]. Additionally, we could corroborate an often-observed relative increase of Actinobacteria compared to healthy controls $[4,5,7]$. Many species of the phylum can produce folate [49]. According to this, an often discussed folate deficiency that can have major adverse effects on the developing human nervous system could not be confirmed in PD [50,51]. Furthermore, also in our cohort, the frequency of the genus Butyricimonas and Odoribacter were tendentially reduced [5]. Both bacteria are producers of short-fatty acids [52,53]. In summary our data support alterations of the microbiome in PD. Therefore, we have tested the influence of a therapy on the microbiome.

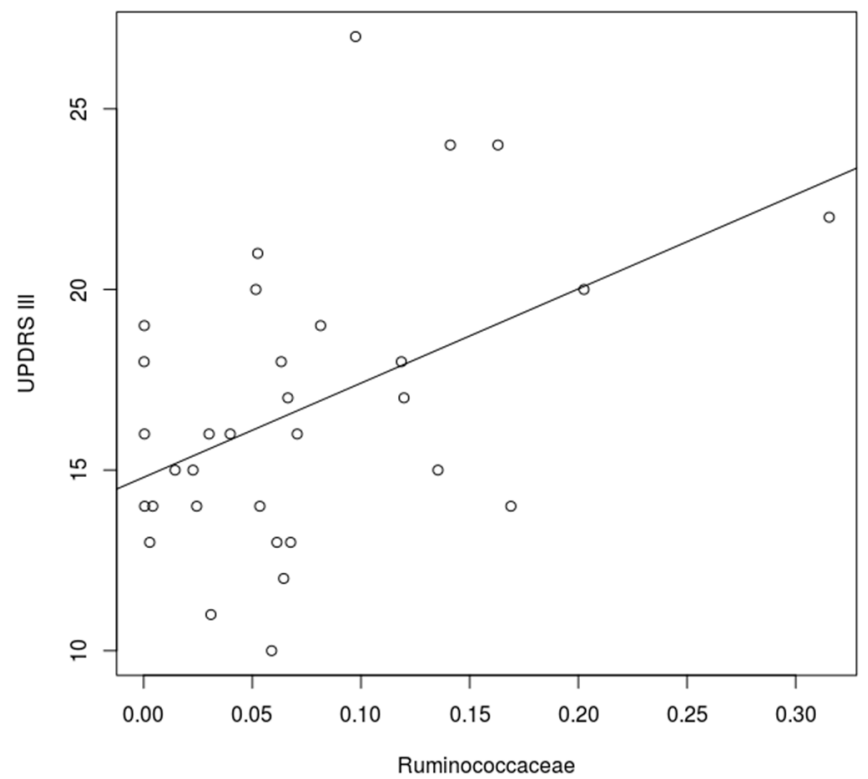

Figure 8. Correlation between frequency of Ruminococcaceae and UPDRS III. There was a significant correlation between the frequency of Ruminococcaceae and UPDRS III in both interventional groups combined $(p=0.003)$.

A well controllable approach to positively influence the microbiome is a vegetarian diet during an inpatient stay. A vegetarian diet appears to be beneficial to human health by promoting the development of a more diverse microbiome [54,55]. Therefore, a positive association has been found between the alpha-diversity and long-term fruit and vegetable intake and Martinez et al. detected an increase of microbial diversity by adding whole-grain barley and brown rice to the diet [56,57]. Furthermore, a pro-inflammatory microbiome has been found in obese participants, with a reduction in the Bacteriodetes:Firmicutes ratio and an increase in Proteobacteria by Verdam et al. [58]. Additionally, non-digestible carbohydrates not only act as prebiotics by promoting the growth of beneficial microorganisms but also reduce proinflammatory cytokine production in humans $[47,59]$. A metabolic product of some intestinal bacteria is SCFA, which is fermented by the families Prevotellaceae and Lachnospiraceae and the genera Akkermansia, Blautia, Roseburia and Faecalibacterium from a fiber-rich diet. All SCFA producers are decreased in PD except the genus Akkermansia [7,42]. Hence, their decrease in PD may be associated with reduced SCFA levels. SCFA are essential for intestinal barrier function, regulation of intestinal motility and immunological processes in the body [60]. They also lead to a down-regulation of pro-inflammatory cytokines (IL-8, IL-6, IL- $1 \beta$, IFN- $\gamma$ and TNF- $\alpha$ ) and the 
promotion of colonic regulatory $\mathrm{T}$ cell differentiation [61,62]. Furthermore, the propionate receptor FFAR3 was discovered on human brain endothelium and an influence of propionate on the BBB via a CD-14-dependent mechanism has been detected [63,64]. In this regard, 500-500 mmol of SCFA are produced in the gut daily, $95 \%$ of SCFAs produced are absorbed within the colon and a level of $17 \mathrm{pmol} / \mathrm{mg}$ butyrate and $18,8 \mathrm{pmol} / \mathrm{mg}$ propionate within the brain tissue have been reported [65]. It has also been shown that oral administration of SCFA promotes the maturation of microglial cells, which are essential for the maintenance of tissue homeostasis within the brain [66]. Additionally, an influence on gene expression, an endocrine (GLP-1, leptin, ghrelin and insulin), a vagal and humoral pathway as well as many transporters and receptors with partly high affinity to the SCFA have been explored [65,67]. A substitution of SCFA might, in addition to already proven neuroprotective effects, also positively influence the course of the disease via its anti-inflammatory action [43,48]. For this reason, we supplemented Ghee including butyrate and propionate to the vegetarian diet [68].

Rectal enemas are a treatment option for patients with IBD (usually with a drug supplement) and another option for influencing the microbiome. Four studies have already shown significant changes in composition and diversity under enemas [69-72]. Additionally, one study has observed changes in intestinal metabolites. Therefore, significant changes including an increase or decrease of 32 metabolites were documented immediately after enema. Most of these metabolites were amino acids [73].

For the first time, we investigated in this proof-of-concept study the influence of an intervention including dietary intervention containing SCFA and enema in a small cohort of patients with PD on the microbiome and related it to the clinical course. Different influences of the microbiome on intestine-associated processes are being considered in the current scientific debate. Increased amounts of pro-inflammatory bacterial species have been determined. As already discussed, influence on inflammatory processes within the intestinal wall and thus indirect influence permeability and might lead potentially to a-synuclein secretion within the intestinal wall. In this respect, in addition to the increase of SCFA through a vegetarian diet, anti-inflammatory effects could be described through a vegetarian diet [10].

Surprisingly, there was no difference in beta-diversity and no significant differences before and after intervention in the relative frequency (Figures 5 and 6). This might be due to the small sample size.

Interestingly, we could detect a negative significant association in the generalized linear model between the Shannon index and the UPDRS III in the combined data of the interventional groups $(p=0.006)$ (Figure 9). Nevertheless, it must be mentioned that besides a strong not significant, negative correlation in the enema group, there was no tendency for correlation in the nutrition group. This could be due to the short intervention period. For example, the influence of enema on the microbiome is already apparent after a few days, whereas the influence of vegetarian diets on the microbiome probably takes a longer [73]. The Shannon index reflects microbial diversity. Therefore, a high microbial diversity or high Shannon index is considered to be healthy [74]. In addition, the UPDRS improved after treatment (Figure 4). Contrary to the stable to increasing levodopa demand as disease progression documented in the literature $[75,76]$, we were able to report a significant reduction of the dopa equivalence dose one year after intervention with enema (Table 4). Nevertheless, an increase of the Shannon-Index before and after therapy could not be documented (Figure 7).

Furthermore, there was a positive correlation between the abundance of Ruminococcaceae and the UPDRS III ( $p=0.0003$ ) (Figure 9). Already, two previous studies have found an increased amount of the species in the intestine in patients with PD [4]. A research group including Hill-Burns found an increase of the amount of Ruminococcaceae associated with disease duration [4]. Considering that the UPDRS III increases during the course of the disease, this strain may be important for possible therapeutic interventions. The abundance of Clostridiaceae was significantly reduced after herbal enema $(p=0.043)$ (Figure S1). Clostridiaceae are a family of the class Clostridia. Further families of this bacterial class are putative proinflammatory bacteria and were documented to be increased in PD [8]. In an animal study Clostridiaceae were more present in dogs with a meat diet and the abundance correlated negatively with 
the levels of SCFA [77]. According to Kesharvzian et al., the reduction of Clostridiaceae might reduce inflammation within the colon and this might reduce alpha-synuclein secretion [8]. At the clinical level, our data show that the UPDRS III improved and decreased significantly after therapy $(p=0.0004)$. An analysis of the subgroup also showed a significant decrease in the group with vegetarian diet $(p=0.033)$ and the group with additional bowel cleansing $(p=0.005)$. However, it must be mentioned that the vegetarian diet group consisted of only 6 patients and has a high standard deviation (Figure 4). The detailed data of the individual changes of the UPDRS III can be seen in Figure S2. According to the recently documented influence of Enterococcus faecalis via tyrosine decarboxylase and Eggerthela lenta via dopamine dehydroxylase on the metabolism of levodopa we could not find any impact on the relative abundance after intervention (Figure S3). Furthermore, no correlation between the levodopa dose and the relative abundance could be detected (Figure S4). According to the presented data a limiting factor in this study is the significant difference in age, since age is considered to be a major influencing factor on the microbiome along with gender [44].
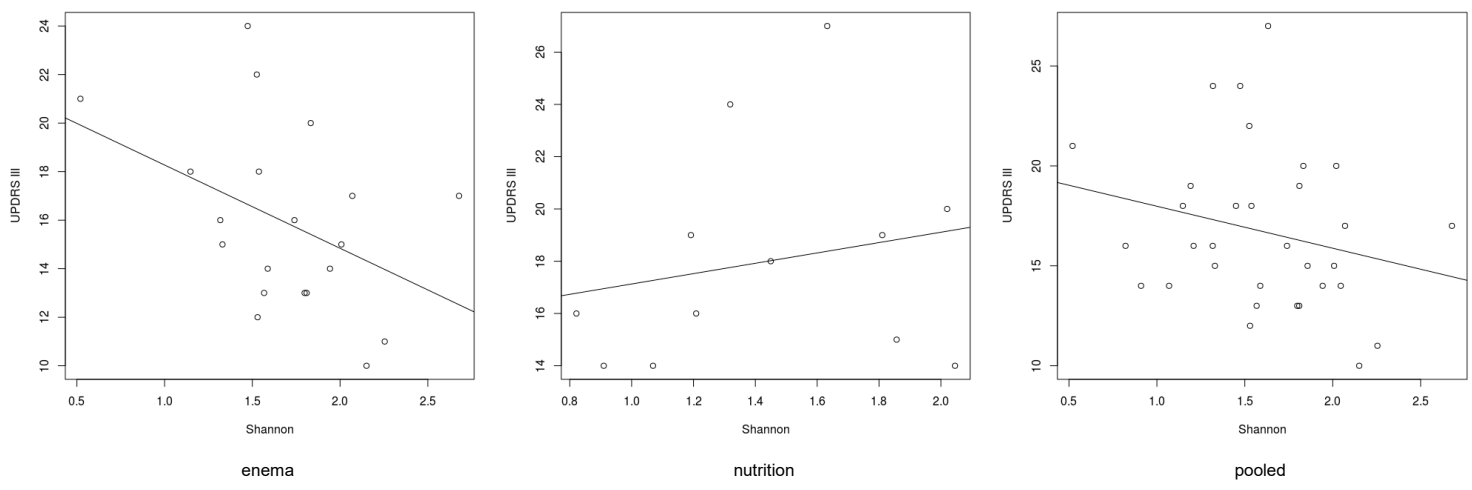

Figure 9. Correlation between the Shannon-Index and the UPDRS III. There was no significant correlation between the Shannon-Index and the UPDRS III but a significant association in the generalized linear model within the pooled group $(p=0.006)$.

In summary, there is growing evidence that changes in the gut microbiome and metabolome may have a direct or indirect impact of the healthy and diseased brain, as is the case for PD. Interventions that may skew the gut microbiome composition and may have a therapeutic effect on the course of the disease. Although small in size, our proof-of-concept study suggests that bowel cleansing, a well-established treatment and good tolerable intervention, in combination with a dietary intervention including SCFA have a positive effective not only on the gut microbiome but may also have a beneficial effect on the clinical course in PD. Nevertheless, as mentioned above the potential side effects including orthostatic dysregulation, electrolyte imbalance, exsiccosis, infections, abdominal pain, diarrhea, nausea and vomiting must be considered.

\section{Limitations}

One limitation of our study is the significant age difference of the two groups, because previous studies have shown age and sex related changes in the microbiome $[44,78]$. Furthermore, it is also important to mention that the intervention group is too small to make definitive statements with a case number of 16 participants and that moderate changes of the microbiome can develop over disease stage.

\section{Conclusions}

As already proven in previous studies, dysbiosis is present in patients with PD. Additionally, a link between the microbiome and the clinical course seems likely. Dietary intervention and bowel cleansing are sufficient methods to impact the gut microbiome in patients with PD. Therefore, a positive 
impact on the clinical course is feasible. Nevertheless, studies with a greater case number are needed for sufficient conclusions.

Supplementary Materials: The following are available online at http://www.mdpi.com/2073-4409/9/2/376/s1, Figure S1: Relative abundance of Clostridiaceae before and after therapy $\left({ }^{*} p<0.05 ;{ }^{* *} p<0.01\right)$. Figure S2: UPDRS III before and after the interventional interval of 14 days. Figure S3: Relative abundance of the level in patients with Parkinson disease before and after intervention. Figure S4: Correlation between the rel. abundance of Eggerthela lenta and the cum. levodopa dose [mg] at the top for both groups.

Author Contributions: T.H.: drafting/revising the manuscript; study concept or design; analysis or interpretation of data; accepts responsibility for conduct of research and will give final approval; acquisition of data; study supervision. M.L.: study concept or design; analysis or interpretation of data; acquisition of data; study supervision. A.D.: drafting/revising the manuscript; analysis or interpretation of data. L.T.: drafting/revising the manuscript. L.T.: drafting/revising the manuscript. J.B.H.: analysis or interpretation of data. H.B.N.: analysis or interpretation of data. S.G.G.: analysis or interpretation of data. H.P.: drafting/revising the manuscript; study concept or design; study supervision. A.H.: drafting/revising the manuscript; study concept or design; accepts responsibility for conduct of research and will give final approval; study supervision. All authors have read and agreed to the published version of the manuscript.

Funding: This research received no external funding.

Acknowledgments: We thank the individuals who participated in this study for their consent and cooperation. We acknowledge support by the DFG Open Access Publication Funds of the Ruhr-Universität Bochum. Furthermore, the study was funded by the German Parkinson Association and FoRUM (Ruhr-University Bochum).

Conflicts of Interest: The authors declare no conflict of interest.

\section{References}

1. Poewe, W. Non-motor symptoms in Parkinson's disease. Eur. J. Neurol. 2008, 15 (Suppl. 1), 14-20. [CrossRef] [PubMed]

2. Kieburtz, K.; Wunderle, K.B. Parkinson's disease: Evidence for environmental risk factors. Mov. Disord. Off. J. Mov. Disord. Soc. 2013, 28, 8-13. [CrossRef] [PubMed]

3. Cersosimo, M.G.; Raina, G.B.; Pecci, C.; Pellene, A.; Calandra, C.R.; Gutiérrez, C.; Micheli, F.E.; Benarroch, E.E. Gastrointestinal manifestations in Parkinson's disease: Prevalence and occurrence before motor symptoms. J. Neurol. 2013, 260, 1332-1338. [CrossRef] [PubMed]

4. Hill-Burns, E.M.; Debelius, J.W.; Morton, J.T.; Wissemann, W.T.; Lewis, M.R.; Wallen, Z.D.; Peddada, S.D.; Factor, S.A.; Molho, E.; Zabetian, C.P.; et al. Parkinson's disease and Parkinson's disease medications have distinct signatures of the gut microbiome. Mov. Disord. 2017, 32, 739-749. [CrossRef] [PubMed]

5. Petrov, V.A.; Saltykova, I.V.; Zhukova, I.A.; Alifirova, V.M.; Zhukova, N.G.; Dorofeeva, Y.B.; Tyakht, A.V.; Kovarsky, B.A.; Alekseev, D.G.; Kostryukova, E.S.; et al. Analysis of Gut Microbiota in Patients with Parkinson's Disease. Bull. Exp. Biol. Med. 2017, 162, 734-737. [CrossRef] [PubMed]

6. Hasegawa, S.; Goto, S.; Tsuji, H.; Okuno, T.; Asahara, T.; Nomoto, K.; Shibata, A.; Fujisawa, Y.; Minato, T.; Okamoto, A.; et al. Intestinal Dysbiosis and Lowered Serum Lipopolysaccharide-Binding Protein in Parkinson's Disease. PLoS ONE 2015, 10, e0142164. [CrossRef]

7. Unger, M.M.; Spiegel, J.; Dillmann, K.U.; Grundmann, D.; Philippeit, H.; Bürmann, J.; Faßbender, K.; Schwiertz, A.; Schäfer, K.H. Short chain fatty acids and gut microbiota differ between patients with Parkinson's disease and age-matched controls. Parkinsonism Relat. Disord. 2016, 32, 66-72. [CrossRef]

8. Keshavarzian, A.; Green, S.J.; Engen, P.A.; Voigt, R.M.; Naqib, A.; Forsyth, C.B.; Mutlu, E.; Shannon, K.M. Colonic bacterial composition in Parkinson's disease. Mov. Disord. 2015, 30, 1351-1360. [CrossRef]

9. Hopfner, F.; Künstner, A.; Müller, S.H.; Künzel, S.; Zeuner, K.E.; Margraf, N.G.; Deuschl, G.; Baines, J.F.; Kuhlenbäumer, G. Gut microbiota in Parkinson disease in a northern German cohort. Brain Res. 2017, 1667, 41-45. [CrossRef]

10. Sender, R.; Fuchs, S.; Milo, R. Are We Really Vastly Outnumbered? Revisiting the Ratio of Bacterial to Host Cells in Humans. Cell 2016, 164, 337-340. [CrossRef]

11. Garrido-Gil, P.; Rodriguez-Perez, A.I.; Dominguez-Meijide, A.; Guerra, M.J.; Labandeira-Garcia, J.L. Bidirectional Neural Interaction Between Central Dopaminergic and Gut Lesions in Parkinson's Disease Models. Mol. Neurobiol. 2018, 55, 7297-7316. [CrossRef] [PubMed] 
12. Qin, J.; Li, R.; Raes, J.; Arumugam, M.; Burgdorf, K.S.; Manichanh, C.; Nielsen, T.; Pons, N.; Levenez, F.; Yamada, T.; et al. A human gut microbial gene catalogue established by metagenomic sequencing. Nature 2010, 464, 59-65. [CrossRef] [PubMed]

13. Braak, H.; Rüb, U.; Gai, W.P.; Del Tredici, K. Idiopathic Parkinson's disease: Possible routes by which vulnerable neuronal types may be subject to neuroinvasion by an unknown pathogen. J. Neural Transm. (Vienna) 2003, 110, 517-536. [CrossRef] [PubMed]

14. Shannon, K.M.; Keshavarzian, A.; Dodiya, H.B.; Jakate, S.; Kordower, J.H. Is alpha-synuclein in the colon a biomarker for premotor Parkinson's disease? Evidence from 3 cases. Mov. Disord. Off. J. Mov. Disord. Soc. 2012, 27, 716-719. [CrossRef]

15. Svensson, E.; Horváth-Puhó, E.; Thomsen, R.W.; Djurhuus, J.C.; Pedersen, L.; Borghammer, P.; Sørensen, H.T. Vagotomy and subsequent risk of Parkinson's disease. Ann. Neurol. 2015, 78, 522-529. [CrossRef]

16. Liu, B.; Fang, F.; Pedersen, N.L.; Tillander, A.; Ludvigsson, J.F.; Ekbom, A.; Svenningsson, P.; Chen, H.; Wirdefeldt, K. Vagotomy and Parkinson disease: A Swedish register-based matched-cohort study. Neurology 2017, 88, 1996-2002. [CrossRef]

17. Santos, S.F.; de Oliveira, H.L.; Yamada, E.S.; Neves, B.C.; Pereira, A. The Gut and Parkinson's Disease-A Bidirectional Pathway. Front. Neurol. 2019, 10, 574. [CrossRef]

18. Bodea, L.G.; Wang, Y.; Linnartz-Gerlach, B.; Kopatz, J.; Sinkkonen, L.; Musgrove, R.; Kaoma, T.; Muller, A.; Vallar, L.; Di Monte, D.A.; et al. Neurodegeneration by activation of the microglial complement-phagosome pathway. J. Neurosci. 2014, 34, 8546-8556. [CrossRef]

19. Alvarez-Arellano, L.; Maldonado-Bernal, C. Helicobacter pylori and neurological diseases: Married by the laws of inflammation. World J. Gastrointest. Pathophysiol. 2014, 5, 400-404. [CrossRef]

20. Lin, J.C.; Lin, C.S.; Hsu, C.W.; Lin, C.L.; Kao, C.H. Association Between Parkinson's Disease and Inflammatory Bowel Disease: A Nationwide Taiwanese Retrospective Cohort Study. Inflamm. Bowel Dis. 2016, 22, 1049-1055. [CrossRef]

21. Schwiertz, A.; Spiegel, J.; Dillmann, U.; Grundmann, D.; Bürmann, J.; Faßbender, K.; Schäfer, K.H.; Unger, M.M. Fecal markers of intestinal inflammation and intestinal permeability are elevated in Parkinson's disease. Parkinsonism Relat. Disord. 2018, 50, 104-107. [CrossRef] [PubMed]

22. Mulak, A.; Koszewicz, M.; Panek-Jeziorna, M.; Koziorowska-Gawron, E.; Budrewicz, S. Fecal Calprotectin as a Marker of the Gut Immune System Activation Is Elevated in Parkinson's Disease. Front. Neurosci. 2019, 13, 992. [CrossRef] [PubMed]

23. Houser, M.C.; Chang, J.; Factor, S.A.; Molho, E.S.; Zabetian, C.P.; Hill-Burns, E.M.; Payami, H.; Hertzberg, V.S.; Tansey, M.G. Stool Immune Profiles Evince Gastrointestinal Inflammation in Parkinson's Disease. Mov. Disord. 2018, 33, 793-804. [CrossRef] [PubMed]

24. Devos, D.; Lebouvier, T.; Lardeux, B.; Biraud, M.; Rouaud, T.; Pouclet, H.; Coron, E.; Bruley des Varannes, S.; Naveilhan, P.; Nguyen, J.M.; et al. Colonic inflammation in Parkinson's disease. Neurobiol. Dis. 2013, 50, 42-48. [CrossRef]

25. Clairembault, T.; Leclair-Visonneau, L.; Coron, E.; Bourreille, A.; Le Dily, S.; Vavasseur, F.; Heymann, M.F.; Neunlist, M.; Derkinderen, P. Structural alterations of the intestinal epithelial barrier in Parkinson's disease. Acta Neuropathol. Commun. 2015, 3, 12. [CrossRef]

26. Salat-Foix, D.; Suchowersky, O. The management of gastrointestinal symptoms in Parkinson's disease. Expert Rev. Neurother. 2012, 12, 239-248. [CrossRef]

27. Forsyth, C.B.; Shannon, K.M.; Kordower, J.H.; Voigt, R.M.; Shaikh, M.; Jaglin, J.A.; Estes, J.D.; Dodiya, H.B.; Keshavarzian, A. Increased intestinal permeability correlates with sigmoid mucosa alpha-synuclein staining and endotoxin exposure markers in early Parkinson's disease. PLoS ONE 2011, 6, e28032. [CrossRef]

28. Williams-Gray, C.H.; Wijeyekoon, R.; Yarnall, A.J.; Lawson, R.A.; Breen, D.P.; Evans, J.R.; Cummins, G.A.; Duncan, G.W.; Khoo, T.K.; Burn, D.J.; et al. Serum immune markers and disease progression in an incident Parkinson's disease cohort (ICICLE-PD). Mov. Disord. 2016, 31, 995-1003. [CrossRef]

29. Brodacki, B.; Staszewski, J.; Toczyłowska, B.; Kozłowska, E.; Drela, N.; Chalimoniuk, M.; Stepien, A. Serum interleukin (IL-2, IL-10, IL-6, IL-4), TNFalpha and INFgamma concentrations are elevated in patients with atypical and idiopathic parkinsonism. Neurosci. Lett. 2008, 441, 158-162. [CrossRef]

30. Sampson, T.R.; Debelius, J.W.; Thron, T.; Janssen, S.; Shastri, G.G.; Ilhan, Z.E.; Challis, C.; Schretter, C.E.; Rocha, S.; Gradinaru, V.; et al. Gut Microbiota Regulate Motor Deficits and Neuroinflammation in a Model of Parkinson's Disease. Cell 2016, 167, 1469-1480.e1412. [CrossRef] 
31. van Kessel, S.P.; Frye, A.K.; El-Gendy, A.O.; Castejon, M.; Keshavarzian, A.; van Dijk, G.; El Aidy, S. Gut bacterial tyrosine decarboxylases restrict levels of levodopa in the treatment of Parkinson's disease. Nat. Commun. 2019, 10, 310. [CrossRef] [PubMed]

32. Maini Rekdal, V.; Bess, E.N.; Bisanz, J.E.; Turnbaugh, P.J.; Balskus, E.P. Discovery and inhibition of an interspecies gut bacterial pathway for Levodopa metabolism. Science 2019, 364. [CrossRef] [PubMed]

33. Lewis, S.J.; Heaton, K.W. Stool form scale as a useful guide to intestinal transit time. Scand. J. Gastroenterol. 1997, 32, 920-924. [CrossRef] [PubMed]

34. Ramaker, C.; Marinus, J.; Stiggelbout, A.M.; Van Hilten, B.J. Systematic evaluation of rating scales for impairment and disability in Parkinson's disease. Mov. Disord. 2002, 17, 867-876. [CrossRef]

35. Edgar, R.C. UPARSE: Highly accurate OTU sequences from microbial amplicon reads. Nat. Methods 2013, 10, 996-998. [CrossRef]

36. Schloss, P.D.; Westcott, S.L.; Ryabin, T.; Hall, J.R.; Hartmann, M.; Hollister, E.B.; Lesniewski, R.A.; Oakley, B.B.; Parks, D.H.; Robinson, C.J.; et al. Introducing mothur: Open-source, platform-independent, community-supported software for describing and comparing microbial communities. Appl. Environ. Microbiol. 2009, 75, 7537-7541. [CrossRef]

37. Cole, J.R.; Wang, Q.; Fish, J.A.; Chai, B.; McGarrell, D.M.; Sun, Y.; Brown, C.T.; Porras-Alfaro, A.; Kuske, C.R.; Tiedje, J.M. Ribosomal Database Project: Data and tools for high throughput rRNA analysis. Nucleic Acids Res. 2014, 42, D633-D642. [CrossRef]

38. Edgar, R.C.; Haas, B.J.; Clemente, J.C.; Quince, C.; Knight, R. UCHIME improves sensitivity and speed of chimera detection. Bioinformatics 2011, 27, 2194-2200. [CrossRef]

39. Wang, Q.; Garrity, G.M.; Tiedje, J.M.; Cole, J.R. Naive Bayesian classifier for rapid assignment of rRNA sequences into the new bacterial taxonomy. Appl. Environ. Microbiol. 2007, 73, 5261-5267. [CrossRef]

40. Cox, L.M.; Weiner, H.L. Microbiota Signaling Pathways that Influence Neurologic Disease. Neurotherapeutics 2018, 15, 135-145. [CrossRef]

41. Houser, M.C.; Tansey, M.G. The gut-brain axis: Is intestinal inflammation a silent driver of Parkinson's disease pathogenesis? NPJ Parkinsons Dis. 2017, 3, 3. [CrossRef] [PubMed]

42. Vital, M.; Karch, A.; Pieper, D.H. Colonic Butyrate-Producing Communities in Humans: An Overview Using Omics Data. mSystems 2017, 2. [CrossRef] [PubMed]

43. Andoh, A.; Bamba, T.; Sasaki, M. Physiological and anti-inflammatory roles of dietary fiber and butyrate in intestinal functions. JPEN J. Parenter Enteral Nutr. 1999, 23, S70-S73. [CrossRef]

44. Rizzatti, G.; Lopetuso, L.R.; Gibiino, G.; Binda, C.; Gasbarrini, A. Proteobacteria: A Common Factor in Human Diseases. Biomed. Res. Int. 2017, 2017, 9351507. [CrossRef] [PubMed]

45. Kim, S.J.; Kim, S.E.; Kim, A.R.; Kang, S.; Park, M.Y.; Sung, M.K. Dietary fat intake and age modulate the composition of the gut microbiota and colonic inflammation in C57BL/6J mice. BMC Microbiol. 2019, 19, 193. [CrossRef] [PubMed]

46. Yatsunenko, T.; Rey, F.E.; Manary, M.J.; Trehan, I.; Dominguez-Bello, M.G.; Contreras, M.; Magris, M.; Hidalgo, G.; Baldassano, R.N.; Anokhin, A.P.; et al. Human gut microbiome viewed across age and geography. Nature 2012, 486, 222-227. [CrossRef]

47. Pagliai, G.; Russo, E.; Niccolai, E.; Dinu, M.; Di Pilato, V.; Magrini, A.; Bartolucci, G.; Baldi, S.; Menicatti, M.; Giusti, B.; et al. Influence of a 3-month low-calorie Mediterranean diet compared to the vegetarian diet on human gut microbiota and SCFA: The CARDIVEG Study. Eur. J. Nutr. 2019. [CrossRef]

48. Kelly, C.J.; Zheng, L.; Campbell, E.L.; Saeedi, B.; Scholz, C.C.; Bayless, A.J.; Wilson, K.E.; Glover, L.E.; Kominsky, D.J.; Magnuson, A.; et al. Crosstalk between Microbiota-Derived Short-Chain Fatty Acids and Intestinal Epithelial HIF Augments Tissue Barrier Function. Cell Host Microbe 2015, 17, 662-671. [CrossRef]

49. Gerhardt, S.; Mohajeri, M.H. Changes of Colonic Bacterial Composition in Parkinson's Disease and Other Neurodegenerative Diseases. Nutrients 2018, 10, 708. [CrossRef]

50. Chen, H.; Zhang, S.M.; Schwarzschild, M.A.; Hernán, M.A.; Logroscino, G.; Willett, W.C.; Ascherio, A. Folate intake and risk of Parkinson's disease. Am. J. Epidemiol. 2004, 160, 368-375. [CrossRef]

51. Greenblatt, J.M.; Huffman, L.C.; Reiss, A.L. Folic acid in neurodevelopment and child psychiatry. Prog. Neuropsychopharmacol. Biol. Psychiatry 1994, 18, 647-660. [CrossRef]

52. Goffredo, M.; Mass, K.; Parks, E.J.; Wagner, D.A.; McClure, E.A.; Graf, J.; Savoye, M.; Pierpont, B.; Cline, G.; Santoro, N. Role of Gut Microbiota and Short Chain Fatty Acids in Modulating Energy Harvest and Fat Partitioning in Youth. J. Clin. Endocrinol. Metab. 2016, 101, 4367-4376. [CrossRef] 
53. Feng, W.; Ao, H.; Peng, C. Gut Microbiota, Short-Chain Fatty Acids and Herbal Medicines. Front. Pharmacol. 2018, 9, 1354. [CrossRef] [PubMed]

54. Derrien, M.; Veiga, P. Rethinking Diet to Aid Human-Microbe Symbiosis. Trends Microbiol. 2017, 25, $100-112$. [CrossRef]

55. Wong, M.W.; Yi, C.H.; Liu, T.T.; Lei, W.Y.; Hung, J.S.; Lin, C.L.; Lin, S.Z.; Chen, C.L. Impact of vegan diets on gut microbiota: An update on the clinical implications. Ci Ji Yi Xue Za Zhi 2018, 30, 200-203. [CrossRef] [PubMed]

56. Martínez, I.; Lattimer, J.M.; Hubach, K.L.; Case, J.A.; Yang, J.; Weber, C.G.; Louk, J.A.; Rose, D.J.; Kyureghian, G.; Peterson, D.A.; et al. Gut microbiome composition is linked to whole grain-induced immunological improvements. ISME J. 2013, 7, 269-280. [CrossRef]

57. Klimenko, N.S.; Tyakht, A.V.; Popenko, A.S.; Vasiliev, A.S.; Altukhov, I.A.; Ischenko, D.S.; Shashkova, T.I.; Efimova, D.A.; Nikogosov, D.A.; Osipenko, D.A.; et al. Microbiome Responses to an Uncontrolled Short-Term Diet Intervention in the Frame of the Citizen Science Project. Nutrients 2018, 10, 576. [CrossRef]

58. Verdam, F.J.; Fuentes, S.; de Jonge, C.; Zoetendal, E.G.; Erbil, R.; Greve, J.W.; Buurman, W.A.; de Vos, W.M.; Rensen, S.S. Human intestinal microbiota composition is associated with local and systemic inflammation in obesity. Obesity (Silver Spring) 2013, 21, E607-E615. [CrossRef]

59. Singh, R.K.; Chang, H.W.; Yan, D.; Lee, K.M.; Ucmak, D.; Wong, K.; Abrouk, M.; Farahnik, B.; Nakamura, M.; Zhu, T.H.; et al. Influence of diet on the gut microbiome and implications for human health. J. Transl. Med. 2017, 15, 73. [CrossRef]

60. Canani, R.B.; Costanzo, M.D.; Leone, L.; Pedata, M.; Meli, R.; Calignano, A. Potential beneficial effects of butyrate in intestinal and extraintestinal diseases. World J. Gastroenterol. 2011, 17, 1519-1528. [CrossRef]

61. Haghikia, A.; Jörg, S.; Duscha, A.; Berg, J.; Manzel, A.; Waschbisch, A.; Hammer, A.; Lee, D.H.; May, C.; Wilck, N.; et al. Dietary Fatty Acids Directly Impact Central Nervous System Autoimmunity via the Small Intestine. Immunity 2015, 43, 817-829. [CrossRef] [PubMed]

62. Louis, P.; Hold, G.L.; Flint, H.J. The gut microbiota, bacterial metabolites and colorectal cancer. Nat. Rev. Microbiol. 2014, 12, 661-672. [CrossRef] [PubMed]

63. Hoyles, L.; Snelling, T.; Umlai, U.K.; Nicholson, J.K.; Carding, S.R.; Glen, R.C.; McArthur, S. Microbiome-host systems interactions: Protective effects of propionate upon the blood-brain barrier. Microbiome 2018, 6, 55. [CrossRef]

64. Brown, A.J.; Goldsworthy, S.M.; Barnes, A.A.; Eilert, M.M.; Tcheang, L.; Daniels, D.; Muir, A.I.; Wigglesworth, M.J.; Kinghorn, I.; Fraser, N.J.; et al. The Orphan G protein-coupled receptors GPR41 and GPR43 are activated by propionate and other short chain carboxylic acids. J. Biol. Chem. 2003, 278, 11312-11319. [CrossRef]

65. Dalile, B.; Van Oudenhove, L.; Vervliet, B.; Verbeke, K. The role of short-chain fatty acids in microbiota-gut-brain communication. Nat. Rev. Gastroenterol. Hepatol. 2019, 16, 461-478. [CrossRef]

66. Erny, D.; Hrabě de Angelis, A.L.; Prinz, M. Communicating systems in the body: How microbiota and microglia cooperate. Immunology 2017, 150, 7-15. [CrossRef]

67. Stilling, R.M.; van de Wouw, M.; Clarke, G.; Stanton, C.; Dinan, T.G.; Cryan, J.F. The neuropharmacology of butyrate: The bread and butter of the microbiota-gut-brain axis? Neurochem. Int. 2016, 99, 110-132. [CrossRef]

68. Andrewes, P. Changes in Maillard reaction products in ghee during storage. Food Chem. 2012, 135, 921-928. [CrossRef]

69. Gorkiewicz, G.; Thallinger, G.G.; Trajanoski, S.; Lackner, S.; Stocker, G.; Hinterleitner, T.; Gülly, C.; Högenauer, C. Alterations in the colonic microbiota in response to osmotic diarrhea. PLoS ONE 2013, 8, e55817. [CrossRef]

70. Shobar, R.M.; Velineni, S.; Keshavarzian, A.; Swanson, G.; DeMeo, M.T.; Melson, J.E.; Losurdo, J.; Engen, P.A.; Sun, Y.; Koenig, L.; et al. The Effects of Bowel Preparation on Microbiota-Related Metrics Differ in Health and in Inflammatory Bowel Disease and for the Mucosal and Luminal Microbiota Compartments. Clin. Transl. Gastroenterol. 2016, 7, e143. [CrossRef]

71. Drago, L.; Toscano, M.; De Grandi, R.; Casini, V.; Pace, F. Persisting changes of intestinal microbiota after bowel lavage and colonoscopy. Eur J. Gastroenterol. Hepatol. 2016, 28, 532-537. [CrossRef] [PubMed] 
72. Harrell, L.; Wang, Y.; Antonopoulos, D.; Young, V.; Lichtenstein, L.; Huang, Y.; Hanauer, S.; Chang, E. Standard colonic lavage alters the natural state of mucosal-associated microbiota in the human colon. PLoS ONE 2012, 7, e32545. [CrossRef] [PubMed]

73. Nagata, N.; Tohya, M.; Fukuda, S.; Suda, W.; Nishijima, S.; Takeuchi, F.; Ohsugi, M.; Tsujimoto, T.; Nakamura, T.; Shimomura, A.; et al. Effects of bowel preparation on the human gut microbiome and metabolome. Sci. Rep. 2019, 9, 4042. [CrossRef] [PubMed]

74. Reese, A.T.; Dunn, R.R. Drivers of Microbiome Biodiversity: A Review of General Rules, Feces and Ignorance. MBio 2018, 9. [CrossRef]

75. Vorovenci, R.J.; Biundo, R.; Antonini, A. Therapy-resistant symptoms in Parkinson's disease. J. Neural Transm. (Vienna) 2016, 123, 19-30. [CrossRef]

76. Nonnekes, J.; Timmer, M.H.; de Vries, N.M.; Rascol, O.; Helmich, R.C.; Bloem, B.R. Unmasking levodopa resistance in Parkinson's disease. Mov. Disord. 2016, 31, 1602-1609. [CrossRef]

77. Bermingham, E.N.; Maclean, P.; Thomas, D.G.; Cave, N.J.; Young, W. Key bacterial families (Clostridiaceae, Erysipelotrichaceae and Bacteroidaceae) are related to the digestion of protein and energy in dogs. PeerJ 2017, 5, e3019. [CrossRef]

78. Odamaki, T.; Kato, K.; Sugahara, H.; Hashikura, N.; Takahashi, S.; Xiao, J.Z.; Abe, F.; Osawa, R. Age-related changes in gut microbiota composition from newborn to centenarian: A cross-sectional study. BMC Microbiol. 2016, 16, 90. [CrossRef] [PubMed]

(C) 2020 by the authors. Licensee MDPI, Basel, Switzerland. This article is an open access article distributed under the terms and conditions of the Creative Commons Attribution (CC BY) license (http://creativecommons.org/licenses/by/4.0/). 